\title{
PARENTS PERCEPTION OF E-LEARNING IN ABU DHABI SCHOOLS IN UNITED ARAB EMIRATES
}

\author{
Asma Khaleel Abdallah \\ Dr., Abu Dhabi University, United Arab Emirates, asma.abdallah@adu.ac.ae
}

\begin{abstract}
The need for learning has been increased with the rapid growth of modern technology and knowledge. Elearning has dramatically changed the manner and process of delivering learning courses and imparting necessary knowledge. The speed, time and distance related issues have been greatly resolved through it. United Arab Emirates, has stated to adopt the E-learning system.

For this purpose, underlying research questions are prepared and answered demonstrating how e-learning contributes in enhancing effectiveness of education and understanding levels. The study aims to investigate parent's understanding and perception of supporting, encouraging and adopting e-learning initiative. It has used primary and secondary data sources; The primary data based on response of 1520 parents, to a questionnaire survey that consists of six domains; 1-students' computer competence, 2-teacher computer competence, 3-quality of teaching and learning, 4-meeting students' needs through the curriculum, 5-school environment, and 6-students' personal development. The secondary data was from data and survey findings from published by academicians focus on parents' perception, difference and choice in selecting private or public institutions, implications on quality of education. To measure the reliability of the study tool; test retest was used. The scale was re-tested with (175) parents after two weeks from the 1st test. By using Spearman-Brown formula $\alpha=(0.9)$ which is acceptable for the purpose of this study.

The results showed that parents' satisfaction was moderate with teacher computer competence whereas they are highly satisfied with student computer competence. The students' personal development, meeting students' needs through curriculum, quality of teaching and learning all these domains showed parents' low satisfaction as per the results. The hypothesis $(a=0.05)$ denotes that null hypothesis is rejected and concludes that significant difference exist in parents' perception of e-learning in Abu Dhabi between public and private schools. Results showed as well e-learning can improve the quality of students learning according to parents' perception through providing them wide variety accessibility of learning materials. The students are not limited or restricted in any manner, regarding course materials, availability of faculty members, accessibility, and time related issues. They can use and access learning materials $24^{\star} 7$ without any restriction of time or physical barrier. The teachers, professionals and experts are available at one click. It has also identified that students often depict laziness and disinterest in visiting schools and universities campuses on ground of distance factor.
\end{abstract}

Keywords: E-Learning perception, Abu Dhabi Schools, Learning quality. 


\section{INTRODUCTION}

The need for learning has been increased with the rapid growth of modern technology and knowledge but the speed and volume of learning is fluctuating according to Rosenberg (2001). The main challenge that we need to overcome is how to acquire knowledge and skills along with the organization of learning resources to keep up knowledge economy. (Rosenberg, 2001). As a result, technology integration in education has emerged as a successful milestone of imparting quality teaching and educational content. Ideally speaking, technology is an integral element of society, in present time, positioning educational technology as one of the major cornerstone of improving students' performance.

E-Learning is not about incorporation if technology in schools so that it can replace teachers with the technological gadgets. In fact, e-learning is the process through which learning process of students can be made easier. Hence, students may be able to learn new things easily because through E-learning they can get a visualization of most of the things. Moreover, for the betterment of student's e-learning is now incorporated as an essential part of student learning. Abu Dhabi, UAE is considered as a growing country embracing new set technological trends and teaching practices at pioneer level. A recent trend, in this regard, in context to higher education, is setting up e-learning systems for providing students with improved medium of accessing learning content. The major driving factors for this trend in the shift or transformations in students' demographic factors, process of delivering educational content, and innovation, in technology itself. With respect to this, it has triggered many researchers to explore and investigate the phenomenon of e-learning, and, it has found that e-learning is an essential prerequisite for matching pace with global learning environments, if used properly.

According to Abuhassna, Amin \& Wajha (2014), a survey findings presented by National Centre for Education Statistics, found that, approximately $40 \%$ teachers are using computers for creating instructional materials, $35 \%$ for administrative purpose, and other record keeping. In this proportion, novice teachers are found as more likely using computers or Internet for instructional purposes or achieving various teaching objectives. This pace of e-learning is identified as, somewhat, slow or still, in conceiving stage at Abu Dhabi till 2010. A report released by the US Department of Education in 2010 argued that education system of Middle East is featured with hybrid and technical tools, on transferring this responsibility or role performed by the Commission on Telecommunications and Information Technology (Abuhassna, Amin \& Wajha, 2014). This step has reformed the pace of adoption of online teaching and Internet in private and public education institutes highlighted the value of e-learning. Almekhlafi \& Almeqdadi (2010) continued the discussion through asserting the fact that traditional academic institution and newly established are resorting towards the adoption of the concept of e-learning, and, reported that different countries, education institutes and universities in UAE are embracing this change in optimistic manner. Even though, scenario presents a mixed picture where traditional universities and institutions matched quite well with the adoption phase of $e$ learning, and, others, including private education institutes are in the early stage (Almekhlafi \& Almeqdadi, 2010).

Ever since, Internet access became possible, Abu Dhabi has been experiencing good growth in the number of education institutes and people going online. With respect to this, Badri, Qubaisi, Rashedi \& Yang (2014) believed that it is desirable to research and conduct study on parents' perception for e-learning regime.

\subsection{The Problem Statement}

The Aim of this research is to answer the main following question:

What is Parents' perception of E-Learning in Abu Dhabi Schools?

\subsection{Purpose and Significance of the Study}

The study aims to investigate parent's understanding and perception of supporting, encouraging and adopting e-learning initiative. The purpose of this non-experimental quantitative descriptive survey is to gather the needed data reflecting the parents' perceptions of E-Learning in AD schools. The results of this study will help to effectively plan how to increase parents' satisfaction with E-learning. The following will benefit from the results of this study:

Teachers, Parents and it will help Abu Dhabi department of Education and knowledge and ministry of education in UAE in developing their strategies needed to meet the goals as well.

\subsection{Research Questions}

The current study addressed the following question $\mathrm{s}$ 
1. What is parents' perception of E-Learning in Abu Dhabi Schools?

2. Are there any significant differences in the parents' perception of e-learning in Abu Dhabi between public and private schools?

3. How can e-learning improve the quality of students learning according to parents' perception?

\subsection{Identifying and Labelling Variables}

\section{E-Learning}

E-learning refers to the use of the Internet to facilitate classroom communications. Teachers using the Internet can utilize such tools as asynchronous discussions, real-time chat, online testing, and document sharing. These Internet tools may sometimes be referred to as Web-based or Websupported technology. E-learning may enhance the educational experience through the use of computer-communications technology, but face-to-face experience is still required. (Bristol,2005).

Parents: Father or mother, or any caretaker of the offspring.

Parents' perception: Parents mental grasp of E-learning. It's measured by the study scale (perception six subscales model)

Public schools: All schools in Abu Dhabi that are directed, supported and funded by Abu Dhabi Department of Education and Knowledge.

Private Schools: All schools in Abu Dhabi that are a supported by a private organization or private individuals, and supported wholly by the payment of fees but is it under Abu Dhabi Department of Education and Knowledge supervision.

\subsection{Study Community}

Parents for all students in classes 10,11, 12 are the community of the study.

\subsection{Population}

The population for this study includes (1520) parents. Table (1) displays distribution of the population members.

Table 1. Population distribution

\begin{tabular}{|l|c|l|l|}
\hline \multicolumn{1}{|c|}{ District } & \multicolumn{3}{|c|}{ Gender } \\
\cline { 2 - 4 } Abu Dhabi & Male & Female & Total \\
\hline Western Region & 277 & 284 & 561 \\
\hline Al-Ain & 172 & 223 & 395 \\
\hline Total & 284 & 280 & 564 \\
\hline
\end{tabular}

\subsection{Study Tools}

The study used primary and secondary data sources; the primary based on response to a questionnaire designed to measure parents' perspective and delivered in paper format to parents personally. The scale consists of six domains. There are six domains that make up the study tool:

1. Student computer competence.

2. Teacher computer competence.

3. Quality of Teaching and learning.

4. Meeting students' needs through the curriculum.

5. School Environment

6. Students' personal development

Five points Likert scale is used to evaluate each item where " 5 " equals" Strongly agree" and "1" equals "strongly disagree" measures population perception to E-Learning. (Hoesing, 2004). The highest score for 
each subscale is 25 points $\left(5^{*} 6=30\right)$, and the lowest is 6 points $\left(1^{*} 6=6\right)$. Domains were divided into three levels (high, moderate, low); the length of each category was decided according to the following equation: (highest score - Lowest score) / number of levels $=(30-6) / 3=8$. Mean scores at or above 24 indicated a high level of satisfaction. The mean scores between 23.99 and 15 indicated a moderate level of satisfaction, a mean score between 6 and 14.99 showed as suggesting a low level of parents' satisfaction.

The secondary data was from data and survey findings from published by academicians focus on parents' perception, difference, and choice in selecting private or public institutions, implications on quality of education.

\subsection{Validity and Reliability of the Questionnaire}

To measure the reliability of the study tool; test - retest was used. The scale was re-tested with (175) parents after two weeks from the $1^{\text {st }}$ test by using Spearman-Brown formula $\alpha=(0.9)$ which is acceptable for the purpose of this study. Cronbach alpha coefficient of internal constancy was used to measure the internal constancy of the tool as a whole and for the domains.

\section{RESULTS AND DISCUSSION}

Results for the first question:

\subsection{What is Parents' Perception of E-Learning in Abu Dhabi Schools?}

To answer this question, data was collected through questionnaire. The collected findings are analyzed with the help of statistical tools i.e., mean and standard deviation, and it is inferred that parents' satisfaction are moderate with teacher computer competence as mean scores ranged between 23.99 and 15 while they are highly satisfied with student computer competence and school environment as mean scores ranged above 24. However, they are less satisfied with the quality of e-learning in terms of content, teaching procedure, etc. as mean score lies between 6 and 14.99 (Badri, Qubaisi, Rashedi \& Yang, 2014). Results are displayed in table (2).

Table 2. Levels of Parents level of satisfaction

\begin{tabular}{|c|c|c|c|}
\hline Domains & $\mathbf{M}$ & SD & $\begin{array}{l}\text { Level of } \\
\text { satisfaction }\end{array}$ \\
\hline $\begin{array}{l}\text { Student } \\
\text { competence }\end{array}$ & 27.3 & 6.54 & High \\
\hline $\begin{array}{l}\text { Teacher computer } \\
\text { competence }\end{array}$ & 18.8 & 5.93 & Moderate \\
\hline Quality of learning & 10.2 & 5.81 & Low \\
\hline $\begin{array}{l}\text { Meeting of students' } \\
\text { needs through the } \\
\text { curriculum }\end{array}$ & 10.7 & 6.44 & Low \\
\hline School Environment. & 25.8 & 7.67 & High \\
\hline $\begin{array}{ll}\begin{array}{l}\text { Students' } \\
\text { development. }\end{array} & \text { personal }\end{array}$ & 11.6 & 5.98 & Low \\
\hline
\end{tabular}

In terms of literary findings, technology integration in higher and professional education world provides learners with increased opportunity of control learning process, as they can access learning materials as per their ease and convenience. Additionally, it provides 'value' benefits mean learning more in less time and preparing students for matching pace with global learning environments.

As a part of this, Mirza \& Al-Abdulkareem (2011) conducted survey on Zayed University for ascertaining perception of parents on e-learning implications, and, results showed that e-learning enjoys high social values and expectations. The parents of female or girl students at Zayed University asserted that e-learning has opened the new and improved path of learning. As per the norms of the university, female students are not allowed to attend classes or present on the campus after specific working hours. This rule prevails strictly 
and female students are required to follow it on weekdays, and, even on weekends. In the midst of this strict norm and working culture, e-learning has proved a boom through allowing students to interact and present at the campus anywhere, and, at any-time. The students are not bounded or restricted in any manner for interacting with faculty members at specific time period (Mirza \& Al-Abdulkareem, 2011).

Moreover, it has also found that female students at Zayed University are not comfortable with interacting with male faculty members as per their parents' perception. This aspect has also been solved to a great extent by e-learning as female students have successfully handled this situation and, found, as in improved position of participating in in-class discussions. With the help of e-learning management systems, female students developed confidence of posting their opinions on discussion boards as they are not required to speak-up in the classroom. As a result, they become more confident in expressing their ideas and opinions over their shy and hesitant nature.

Moussa-Inaty \& Vega (2013) depicted positive affirmations on above findings and contributed the discussion through stating the fact that advanced capability of e-learning, which has changed parents' perception, is the overcoming of physical factors and hardships. Putting in simple words, students are required to visit the campus physically, before the evolution of e-learning systems. The issue intensifies more in case where education institutes and universities are located at distant locations and, students are forced to visit campuses physically for attending learning courses. There is good proportion of students in Abu Dhabi residing at far miles away, and, founding it quite difficult to regularly attend learning courses. This inability of moving to university campuses and schools has been solved to a great extent by e-learning system (Moussa-Inaty \& Vega, 2013).

\section{Technology acceptance model (TAM)}

The parents' perception towards e-learning is analyzed with the help of technology acceptance model (TAM). The model explains how users accept and use technology for improving outcomes or results. Goldsteen, Dwelle \& Goldsteen (2014) suggested that there are number of factors influence and shape users' perception and decision of adopting and using one technology, and, time they should use it as well as the manner. The model is depicted in the underlying figure:

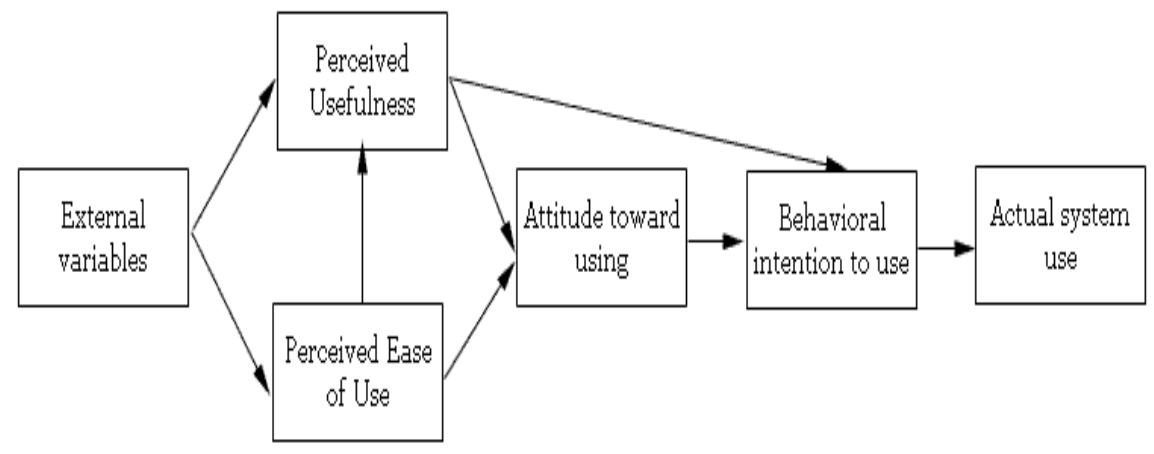

The notable factors, as depicted by the model, are perceived usefulness and perceived ease-of-use. As the title indicates, perceived usefulness is concerned with the degree to which users believe that particular technology or system is capable of enhancing performance, and, perceived ease-of-use is concerned with the belief among user that a particular technology or system is error free, and, its usage will surely benefit or improve performance. These two factors determine the acceptability of an information system. It seems evident as users depict interest in using a system or technology, when they are convinced on both the factors (Goldsteen, Dwelle \& Goldsteen, 2014).

The model is applied for understanding the dynamics of e-learning with the help of theory of reasoned action. The theory of reasoned action has widened the model and outlined that behavioral intention also plays crucial role. As demonstrated by the theory of reasoned action, e-learning adoption in the education institutes in determined by the behavioral intention, which in turn influenced by person's attitude towards use of system and utility. In this regard, parents' perception for e-learning system is not only determined by its use or utility, but also on the basis of its overall implication on performance. In simple words, parents encourage their children for using e-learning system, if they perceive that it will improve their children's performance. On elaborating the model in detailed terms, it has identified that there are several external variables shaping individuals' attitude towards adoption of particular technology or system (The facts behind Emiratis in private schools in Dubai: In Search of Good Education Volume 2, 2012). 
Among the external variables, ease and convenience to use determine users' sense of efficacy. In simple words, e-learning system should appear easy and comfortable to use by children through asserting the fact that more easiness and convenience to use a technology, the greater is the users' sense of efficacy. In addition to it, parents' demonstrated that students should have control over the things means manner of using e-learning and its technology, in order to use it as large scale. The author argued that efficacy serves as the underlying factors behind adopting and using e-learning. It is necessary on the part of parents to accept and convince with the fact that e-learning cause less deployment of efforts and provides a quick tool for accomplishing learning targets. It acts as good time saver for students which can be spent on other activities for improving their performance (Eysenck, 2014).

Gosling, Rentfrow \& Swann (2003) showed that social influence processes including image and norms prevailed in the society, and, cognitive instrumental processes including output quality, result demonstrability, and relevance determines users' perceived usefulness and intention to use. There is thorough evaluation of education outcomes, results, performance improvement, etc at the time of deciding adoption of e-learning. The author has further elaborated the concept and mentioned that there are six contextual variables in terms of prior experience, other's use, computer anxiety, system quality, task structure and organizational support (Gosling, Rentfrow \& Swann, 2003).

In detailed terms, parents having past experience regarding use of e-learning or other technological system is preferred, and, if they have visualized anyone using this technique. Thirdly, it is also necessary that parents should have desired level anxiousness for using e-learning and firm belief regarding e-learning quality. Besides, structural aspect of e-learning and support demonstrated by education institutes and universities for using e-learning also acts as deciding factor in adopting e-learning technology. All these act as independent variables for developing desired mind-set regarding perceived ease to use and perceived usefulness (Gosling, Rentfrow \& Swann, 2003).

Results for the second question:

\subsection{Are There Any Significant Differences in The Parents' Perception of E-Learning in Abu Dhabi Between Public and Private Schools?}

To answer the second question, primary and secondary data sources were used. The primary data was collected through questionnaire. The collected findings are analyzed with the help of statistical tools i.e., mean, standard deviation and One Way Anova. The secondary data was from data and survey findings from published by academicians focus on parents' perception, difference and choice in selecting private or public institutions, implications on quality of education.

The hypothesis $(\mathrm{a}=0.05)$ denotes that null hypothesis is rejected and concludes that significant difference exist in parents' perception of e-learning in Abu Dhabi between public and private schools.

As inferred from the hypothesis $(a=0.05)$, which indicates that there prevail significant differences between private and public schools regarding e-learning. In this regard, research findings of several authors and researchers are pertinent to discuss and analyze for deriving conclusions regarding differences in public and private school adoption of e-learning system. Kise (2014) argued that education institutions at Abu Dhabi are resorting towards adoption of e-learning system as a part of matching pace with global education environment. It is well understood by Abu Dhabi's educational institutes that e-learning is an essential prerequisite of present scenario.

With respect to this, public and private education institutes at Abu Dhabi are frequently adopting measures for placing and implanting e-learning system. The author researched and found that IT adoption is a major source of e-learning adoption. In the study, it is emphasized that Information technology (IT) and necessary infrastructural requirements are placed in adequate level and terms for adopting e-learning. The adequacy of IT is essential for adopting and embracing e-learning in optimum terms. Furthermore, research and investigation of factors influencing e-learning system is the availability of technical support and ease of use. These two factors are considered as strategic in optimally placing and using e-learning effectively (Kise, 2014).

Additional research presented the fact that private and public education institutes vary significantly in terms of availability and adequacy of resources. The resources here refer to financial, technical and human resources requires for initiating and delivering e-learning programs. The resources here include monetary funds and investments required for developing necessary infrastructure for e-learning systems, hiring required personnel, procuring and arranging necessary technical facilities, recruiting professional staff for imparting necessary training and guidance to students for using e-learning, etc (Kutsar, Ghose \& Kutsar, 2014). 
The procurement and arrangement of all these resources require substantial amount funds which is quite difficult for private institutions to arrange. Contrary to this, public institutions are in improved position of arranging and allocating necessary funds required for procuring necessary facilities for e-learning. This factor place public institutions with high degree power, freedom, and authority in making necessary decisions and adopting e-learning system. The power, freedom and authority available to public institutions are attributed to the fact that public institutions are highly empowered and capable for adopting this technique.

On analyzing reasons behind this fact, Leary \& Hoyle (2013) asserted that public institutions are run in collaborative manner through non-government institutes, public forums, government, etc. In other words, public institutions are backed up with strong support of government and policy makers. This strong support does not render any difficulty to public institutions in allocating necessary funds for running e-learning system. The shortage of funds never appeared as an obstructing factor in context to public institutions (Leary \& Hoyle, 2013).

For testing feasibility and validity of this statement, numerous research studies have conducted in order to examine proportion of efforts and measures adopted by public and private institutions. It is worth mentioning that literary studies on e-learning initiatives by public institutions are available in large quantity as compared to private ones witnessing the fact that public institutions are leading this race. Evidently, it is argued that elearning initiative in the Middle East is increasing at rapid pace in the $21^{\text {st }}$ century witnessing growing interest of different governments for running and establishing e-learning projects and programs (Myers \& Myers, 2010).

Abu Dhabi government also does not lag behind in this race and acts as pioneer in conducting heavy efforts for launching and placing e-learning projects and programs. There are numerous cases and examples evidencing this fact and scenario, as Oman Ministry of Education, through partnering relations with Edutech Middle East, a leading provider of technology enabled learning solutions has placed and established elearning solutions in around 590 schools around the country. When it comes to higher education institutes, Abu Dhabi's government is conducting several pilot projects for improving the adoption of e-learning system (Myers \& Myers, 2010).

Schawbel (2013) continued the discussion further through asserting that public institutions enjoy strong standing and position, when it comes to the adoption of e-learning initiatives. The positioning of public institutions improved as there are different models developed by government for e-learning in different parts of the country. The availability of different models empowers public institutions in selecting best possible option from available alternatives. Depending on the students' potential and capability, public institutions can select particular type of e-learning model. Contrary to it, this facility is not available to private institutions as they have to operate in restricted manner due to limited availability of options and alternatives (Schawbel, 2013).

In this regard, author has researched three different e-learning models named as virtual e-learning model, hybrid e-learning model and a traditional university e-learning model. The three models are developed for strengthening the positioning of public institutions and providing them with advanced options for availing elearning technology. Starting with, virtual e-learning model is striving towards establishment of specialized online universities. These universities include establishment of e-TQM in Dubai, UAE, Mediterranean Virtual University, and many more (Sharma, Bottom \& Elfenbein, 2013).

These online universities are dedicated for offering various degrees including bachelor's, master's and diplomas. The degrees at Abu Dhabi education institutes are offered in cooperation with British and American universities such as Ohio University, Robert Gordon University, University of York, and many more. There is no need of visiting campuses in physical terms on the part of students as education courses are imparted online. The most common online courses offered include business and quality management, organizational excellence, public health, innovation and change management.

In the same token, hybrid e-learning model is also introduced for providing public institutions with another set opportunity of availing e-learning system. Under hybrid e-learning model, there is creation of actual physical buildings where students can visit for the purpose of meeting and interacting with faculty members, completing registration process, participating in exams, etc (Abolmaali, Rashedi \& Ajilchi, 2014). There is no compulsion for students to visit physical buildings, they can visit as per their ease and convenience in once in every two weeks. The major responsibility falling upon students, in this regard, is to visit campus for obtaining course materials, interacting with course instructor, getting things clear and submitting assignments. Aran Open University is the most popular education institution following and adhering hybrid elearning model. The headquarters of Arab Open University is located in Kuwait with other branches established in Egypt, Abu Dhabi, Egypt, Oman and Lebanon. It is expected that the Abu Dhabi branch would 
start expecting good number students in the near future, and, expected to emerge as one of the largest education institution across the country (Naseer, Chishti, Rahman \& Jumani, 2011).

Thirdly, traditional university e-learning model in the Middle East is also emerged as another widely accepted e-learning model in UAE. It has found that greatest majority of education universities in UAE have responded to this e-learning model more positively. The most widely manner of using traditional university e-learning model is in the form of providing supporting traditionally attended course with the help of Internet. WebCT is one of the most commonly used traditional university e-learning model, and, till, 2007 there are around 45 students enrolled in it. This number represents visible level of interest of students as well as their parents in e-learning programs and initiatives. This step has been preceded further through launching Microsoft's Learning Gateway Solution, in an attempt to improve e-learning platform (Sharma, Bottom \& Elfenbein, 2013).

Till 2004, e-learning platform has not received adequate attention and high level enthusiasm; however, with the pace of time, e-learning regime has gained momentum. In order to improve the pace of acceptance and adoption of e-learning system, Microsoft Learning Gateway Solution has allotted efforts for developing awareness among students regarding adoption and usage of e-learning system. The complaints and enquiries fostered by students and teachers are sorted and solved in order to motivate them for using elearning system.

In the process of advanced applications and adoption of e-learning system by traditional universities and educational institutes, new project titled as 'Edutech Middle East' is launched for building an e-learning center simulating 'a classroom atmosphere' with the help of digitised and internet enabled e-learning module. The simulation program is equipped with visual and descriptive educational content enabling students to attend and learn with quick ease and convenience. It is purely a customised web based registration system where students are not required to attend physical classes and programs (Clark \& Springer, 2007).

Results for the third question:

\subsection{How Can E-Learning Improve the Quality of Students Learning According to Parents' Perception?}

To answer the third question, secondary data sources was used. The secondary data was from data and survey findings from published by academicians focus on parents' perception, difference and choice in selecting private or public institutions, implications on quality of education.

E-learning has completely transformed or shifted the traditional manner of imparting learning to students. The emergence of e-learning has facilitated and made the process of learning simpler, easier, and effective, unlike the traditional method based on using chalk and board. The flexible nature of e-leaning has embraced students, teachers and parents at large scale through evidencing variety of advantages and positive implications (Kowalski, 2010). The quality of students' learning through e-learning is improved in several manners, such as, fostering advanced learning opportunities, career advancement, flexible and adaptable nature, etc. These features have staggered the growth of e-learning tremendously and replaced traditional teaching methods over the past decade (Fox \& Patterson, 2013).

As per the recent report findings collected by Lytras, De Pablos, Avison, Leal \& Horner (2010) in 2011, major gap in the expected and actual quality of learning is attributed to the fact that learners required wide variety choice and options. Through researching learners' needs and expectations, it has found that they prefer a mobile, quick, personalized, and self-paced content available at their point of need and requirement. These set of expectations are not fulfilled by traditional education method as it is emphasizing highly on face-to-face and long courses with lengthy durations. The digital revolution has triggered huge changes in the manner of accessing, discussing, and sharing content. Now-a-days, learning is following suit through making it available at the point of need i.e., learning in evenings, weekends, at the work or away from the work (Lytras, De Pablos, Avison, Leal \& Horner, 2010).

The key implication of e-learning in improving quality of students' learning is making them synchronized or aligned with modern learners. In detailed terms, students can participate or interact with faculty members located anywhere across the world. They are not bounded or restricted in any manner for interacting with specific faculty members, or participating in particular education courses (Badidi, 2013). Contrary to this, they are allowed to interact with faculty members at any place and accessing any type of content depending on their interest and needs. It also imparts social and collaborative skills among students as they get opportunity to interact, discuss and share with different nature personnel and developing repo with them thereby improving social and collaborative skills (Leadership Update, 2011). 
In the same token, Schwalbe (2016) argued that change is faster than ever at times, and, so is the learning process. The quicker delivery cycle times of e-learning yielded wide array benefits, for example, initiating and wrapping up learning session quickly, providing learners with their own pace, reducing travel time and need of attending training events, and, allowing leaners to focus on elements of course program they wish to learn and skipping content already known to them. All these factors have reduced learning time by at least 15 to 20 per cent thereby provided ease and convenience to students which eventually helped in maintaining and retaining students' interest (Schwalbe, 2016).

This advantageous factor is presented in different terms by Wang \& John (2013) through highlighting the fact that e-learning sets foundation of effective learning. Apart from making learning easy and digestive, elearning has developed positive attitude among learners toward educational courses and programs. Traditional learning courses and its format appear disinteresting and general in nature, contrarily; e-learning format is designed in interesting manner (Wang \& John, 2013). The interactive mode of e-learning along with visual graphics developed positive attitude among learners towards educational courses and programs. The positive attitude among leaners pose long-lasting impact as it increases their interest level, motivates them to perform with improved ability and competitiveness, retaining information for longer time, etc. which eventually result in improved scores on tests and other evaluations (Wang \& John, 2013).

According to Wimmer \& Dominick (2010), e-learning has made the education more readily available through eliminating the word 'impossible' in study process. E-learning fostered the feature of making education or learning available, in case students are only interested in studying a particular course instead of receiving a degree. This is a growing phenomenon among students across the world, and, so is the case with Abu Dhabi students. The urge for knowledge and talent in corporate world and advancing career opportunities necessitate students studying particular course for the reason of advancing and equipping new set knowledge (Wimmer \& Dominick, 2010).

It is not done in lieu of receiving a degree, rather for advancing current set knowledge and awareness. This process is being simplified considerably by e-learning through allowing students to enroll and complete courses designed and offered by world's best universities. In context to native students, i.e., Abu Dhabi, it is proving beneficial for them also as they can communicate, study and interact with people belonging from different cultures. This factor develops skill of multicultural experience among Abu Dhabi students which is one of the essential prerequisite of present scenario. As globalization has embraced business of different culture and backgrounds therefore require personnel strongly backed and proficient in multicultural terms (Luppicini \& Rocci, 2012).

The theme of entertaining has also improved the quality aspect considerably. Although this factor receives less attention from academic practitioners, yet it seems worthwhile mentioning that role of e-learning in making learning process as entertaining and appealing can't be ignored. Generally speaking, students are used to entertaining and interactive themes of education these days unlike to the disinterested theme of traditional education system (Skersys, Butleris \& Butkiene, 2013).

The online education medium provides chance to the students to communicate through chats, online forums and sharing their progress on social media. This feature is highly liked by students and proves as a matter of refreshing in the traditional manner of availing learning courses. In equation terms, the more the diverse nature of educational process, greater it will be interesting for students. Even though, it is merely an addition to the traditional learning, still it holds good potential of bringing nice change (Schacht, 2010).

As per the findings published by US University Boston College, e-learning should be considered as an educational resource benefiting and improving students in terms of professional development. It has found that students availing e-learning courses demonstrate high knowledge and improvement in professional terms. The report stated that series of online professional development courses focusing on specific content and target student brings positive impact on students' knowledge and instructional practices. Overall findings argued that students located in remote setting are also being targeted by e-learning for enabling them to build skill and development sets. The absence of highly qualified teachers in remote setting does not stop or prevent them from availing learning courses or programs (Antonucci, 2016).

E-learning acts as an effective approach for improving learning of students and educators in remote areas as this technique can work in a variety of settings. In this regard, experts argued that e-learning approach of making education accessible and available all the time improves possibility of yielding better results and encouraging learners and educators opting for online education (Tan, Liu \& Sun, 2013). It is worth mentioning that present generation of students and educators prefer spending time glued to gadgets and techniques as a new era hope of connecting with world's events and retrieving required knowledge. Elearning is worth mentioning example in this regard allowing students to virtually carry classes in their 
pockets. One recent report collected by Ambiant insight showed that western educational market is continuously increasing and yielding value of $\$ 958.7$ in 2016, this mammoth rise is predicted to grow more than $10 \%$ in the coming five years (Botha \& Geldenhuys, 2016).

In context to Abu Dhabi, Brea (2014) argued proportion of students convinced with e-learning system is increasing continuously, even in Abu Dhabi as well. For improving facilitating of e-learning, BYOD (Bring your own device) concept is also introduced and used by students' at large scale. It is being adopted hugely by schools and education institutes these days, and, Abu Dhabi also does not lag behind the race (Brea, 2014). The improved features providing option of learning through video instruction and live Internet discussions motivated schools and colleges to avail this option. Sometimes, teacher forget to put up notices on boards which could be done through using e-learning system thereby outlining fact that e-learning system is an essential educational tools in the present decade. The main reason behind increased preference of students for availing e-learning technique is that their generation have grown up in the manner where they are playing, hearing and seeing technology. The growing acquaintance of students with high-tech equipment is a major reason boosting the rise in e-learning (Coronato \& Antonio, 2010).

In sum, it can be said that e-learning proves a great encouragement for students around the world along with Abu Dhabi students as well. The discussion outlined that there are several motivating factors encouraging students opting and preferring e-learning as a complete and integrated learning medium. Among identified factors, it can be said that accessibility, convenience, absence of geographical barriers, physical impediments etc. as prevail in the academic sphere are completely absent in the e-learning sphere (Mihailidis, Boger \& Hoey, 2013). The doors of e-learning are open and accessible to all providing continuous learning opportunity to all without any barrier. It is, therefore, considered as a new age education system providing an updated version of knowledge and learning which students can access at their convenience from different parts of the world. Altogether, e-learning is a blissful learning mechanism for students of all age group and background therefore preferred and adopted at large scale (Stair \& Reynolds, 2015).

\section{CONCLUSION AND RECOMMENDATIONS}

The researcher developed the following conclusions from the findings:

1. Based on parents' perception; parents are un-satisfied with E-learning; at the same time most of the sample members aren't familiar with E-learning.

2. Culture influence parents' perception; in fact, the society culture could be inhibitor of e-learning. Parents' low level of satisfaction with quality of teaching and learning, meeting students' needs, students' personal development and moderate level of satisfaction with teacher computer competence is an indicator of parents' conviction with traditional teaching and learning. Parents view teachers as the authority figure. Venter (2003) mentioned in Dajani (2009) displayed that some cultures are more acceptable for e-learning than others.

3. Parents' high satisfaction with students' computer competence is an indicator of parents understanding of their children interests with new technological devices and their ability to use it easily. Also parents' high level of satisfaction with school environment is an indicator of their high trust with ADEK performance.

4. Multiple steps should occur to ensure a successful implementation. Parents' orientation and training must be provided to support enabling transition to E-Learning. These steps will help to familiarize the people with e-learning, and alter people's views from the negative to the positive. The main goal is not necessarily to transform the views from negative to positive, but to allow the public to understand E-learning. Only then can E-learning grow and positively address and successfully impact the educational issues facing UAE.

5. The result shows significant differences in the parents' perception of e-learning in Abu Dhabi between public and private schools. As a result, private schools need more focus on e-learning and ADEK need to follow and supervise this.

6. E-learning proves a great encouragement for students around the world along with Abu Dhabi students as well. The doors of e-learning are open and accessible to all providing continuous learning opportunity to all without any barrier which will lead to improve learning quality.

7. Finally; more studies related to how e-learning can improve the quality of students learning and students' engagement. 


\section{REFERENCE LIST}

Abolmaali, K., Rashedi, M. \& Ajilchi, B. (2014). Explanation of Academic Achievement Based on Personality Characteristics Psycho-Social Climate of the Classroom and Students' Academic Engagement in Mathematics. Open Journal of Applied Sciences, 4, pp. 225-233.

Abolmaali, K., Rashedi, M. \& Ajilchi, B. (2014). Explanation of Academic Achievement Based on Personality Characteristics Psycho-Social Climate of the Classroom and Students' Academic Engagement in Mathematics. Open Journal of Applied Sciences, 4, pp. 225-233.

Abuhassna, H. M., Amin, I.M.H. \& Wajha, S.K.A. (2014). Parental Perceptions Of The Importance Of Computer Usage In The Educational Process Of Their Children In Elementary Schools: An Exploratory Study. International Journal of Research in Engineering \& Technology. Vol. 2, Issue 9, pp. 65-72 .

Almekhlafi, A.G. \& Almeqdadi, F.A. (2010). Teachers' Perceptions of Technology Integration in the United Arab Emirates School Classrooms. Educational Technology \& Society, 13 (1), 165-175.

Antonucci, D. (2016). Risk Maturity Models: How to Assess Risk Management Effectiveness. Kogan Page Publishers.

Badidi, E. (2013). A framework for software-as-a-service Selection and provisioning. International Journal of Computer Networks \& Communications (IJCNC) Vol.5, No.3.

Badri, M., Qubaisi, A. A., Rashedi, A. A. \& Yang, G. (2014). The causal relationship between parental involvement and children's behavioural adjustment to KG-1 schooling. International Journal of Child Care and Education Policy. Vol. 8, No. 1.

Botha, B. \& Geldenhuys, P.( 2016). Managing E-commerce in Business. UK: Juta and Company Ltd.

Brea, C. (2014). Marketing and Sales Analytics: Proven Techniques and Powerful Applications from Industry Leaders. FT Press.

Bristol, Timoty J. ( 2005). Perception of IOWA Nursing Faculty, Capella University, pp. 5.

http://search.proquest.com.ezproxy.uaeu.ac.ae . 18/10/2017

Clark, C. M., \& Springer, P. J. (2007). Thoughts on incivility: Student and faculty perceptions of uncivil behaviour. Nursing Education Perspectives, 28(2), 93-97.

Coronato \& Antonio. (2010). Pervasive and Smart Technologies for Healthcare: Ubiquitous Methodologies and Tools: Ubiquitous Methodologies and Tools. IGI Global.

Dajani. Nizar.N. (2009). Perception of Arab Students, Faculty Members, and Administrators at the American University in Cairo Towards E-Learning: An Expletory case Study. Cappella University, pp. 119. Review from http://search.proquest.com.ezproxy.uaeu.ac.ae . 18/10/2017

Eysenck, M.W. (2014). Individual Differences: Normal And Abnormal. Psychology Press.

Fox, A. \& Patterson, D.A. (2013). Engineering Software as a Service: An Agile Approach Using Cloud Computing. Strawberry Canyon LLC.

Goldsteen, R., Dwelle, T., \& Goldsteen, K. (2014). Introduction to public health (2nd ed.). New York: Springer Publishing Company. Read: Chapter 1: Introduction and overview; and Chapter 2: Origins of public health.

Gosling, S.D., Rentfrow, P.J. \& Swann, W.B. (2003). A very brief measure of the Big-Five personality domains. Journal of Research in Personality 37, pp. 504-528.

Hoesing. Daniel J. (2004). Student Perception of E-Learning in South Dakota High Schools, University of South Dakota, Dec. 2004. pp.47.Review from: http://search.proquest.com.ezproxy.uaeu.ac.ae . $18 / 10 / 2017$

Kise, J. (2014). Differentiation through Personality Types: A Framework for Instruction, Assessment, and Classroom Management. Skyhorse Publishing, Inc.

Kowalski, T.J. (2010). The School Principal: Visionary Leadership and Competent Management. New York: Taylor \& Francis.

Kutsar, V., Ghose, N. \& Kutsar, Y. (2014). Leadership Analysis Using Management Tools: Steve Jobs. American International Journal of Contemporary Research. Vol. 4 No. 2. 
Leadership Update. (2011). Alberta leadership competencies for school leaders and leadership. The Alberta teachers' association, 7(9). Pp: 1-2.

Leary,M.R. \& Hoyle, R.H. (2013). Handbook of Individual Differences in Social Behavior. Guilford Publications.

Luppicini \& Rocci. (2012). Ethical Impact of Technological Advancements and Applications in Society. IGI Global.

Lytras, M. D., De Pablos, P. O., Avison, D., Leal, W. \& Horner, D. G. (2010). Technology Enhanced Learning: Quality of Teaching and Educational Reform: 1st International Conference, TECHEDUCATION 2010, Athens, Greece, May 19-21, 2010. Proceedings. Greece: Springer.

Mihailidis, A., Boger, J. \& Hoey, J. M. (2013). Information Technology in Environmental Engineering: Selected Contributions to the Sixth International Conference on Information Technologies in Environmental Engineering (ITEE2013). Springer Science \& Business Media.

Mirza, A. A. \& Al-Abdulkareem, M. (2011). Models of e-learning adopted in the Middle East. Applied Computing and Informatics journal, Vol. 9, No. 2. Pp. 83-93.

Moussa-Inaty, J. \& Vega, E.S. L. (2013). From Their Perspective: Parental Involvement in the UAE. International Journal of Sociology of Education, Vol. 2, No. 3, pp. 292-312.

Myers, I.B. \& Myers, P.B. (2010). Gifts Differing: Understanding Personality Type. Hachette UK.

Naseer, Z., Chishti, S. H., Rahman, F. \& Jumani, N,B. (2011). Impact of Emotional Intelligence on Team Performance in Higher Education Institutes. International Online Journal of Educational Sciences, 3(1), pp. 30-46.

Rosenberg, Marc J. (2001). E-Learning Strategies for Delivering Knowledge in the Digital Age. McGraw-Hill, pp. 3.

Schacht, W.H. (2010). Industrial Competitiveness and Technological Advancement: Debate Over Government Policy. DIANE Publishing.

Schawbel, D. (2013). Promote Yourself: The new rules for building an outstanding career. Hachette UK.

Schwalbe, K. (2016). Information technology project management, 8th ed. Boston: Course Technology. Cengage Learning.

Sharma, S., Bottom, W. \& Elfenbein, H.A. (2013). On the role of personality, cognitive ability, and emotional intelligence in predicting negotiation outcomes: A meta-analysis. Organizational Psychology Review 3(4), pp. 293-336.

Sharma, S., Bottom, W. \& Elfenbein, H.A. (2013). On the role of personality, cognitive ability, and emotional intelligence in predicting negotiation outcomes: A meta-analysis. Organizational Psychology Review 3(4), pp. 293-336.

Skersys, T., Butleris, R. \& Butkiene, R. (2013). Information and Software Technologies: 18th International Conference, ICIST 2012, Kaunas, Lithuania, September 13-14, 2012. Proceedings. Springer.

Stair, R. \& Reynolds, G. (2015). Fundamentals of Information Systems. Cengage Learning.

Tan, C., Liu, K. \& Sun, L. (2013). A design of evaluation method for SaaS in cloud computing. Journal of Industrial Engineering and Management JIEM, 6(1), pp. 50-72.

The facts behind Emiratis in private schools in Dubai: In Search of Good Education Volume 2.(2012). Knowledge \& Human Development Authority. Retrieved $25^{\text {th }}$ November 2017 http://www.khda.gov.ae/CMS/WebParts/TextEditor/Documents/Emiratis\%20in\%20Dubai\%20Private\% 20Education\%20_EN\%2031-10-2012\%20(2).pdf Wang \& John. (2013). Perspectives and Techniques for Improving Information Technology Project Management. IGI Global.

Wimmer, R. \& Dominick, J. (2010). Mass Media Research: An Introduction. Cengage Learning. 